\title{
Oficina de Controle de Ansiedade e Enfrentamento do Estresse com Universitários
}

\author{
Taller de Control de Ansiedad y Enfrentamiento del estrés com Universitarios \\ Workshop on Anxiety Control and Coping Stress with University Studentes
}

Fabiana Pinheiro Ramos

ORCID: http://orcid.org/0000-0002-2233-0305

Universidade Federal do Espírito Santo, Espírito Santo/Brasil

\author{
Nayara Stefenoni Kuster \\ ORCID: https://orcid.org/0000-0002-1333-0979 \\ Prefeitura Municipal de Colatina, Espírito Santo/Brasil
}

Juliana Nascimento Lucas Ramalhete

ORCID: https://orcid.org/0000-0001-5648-6087

Fundação de Amparo à Pesquisa do Espírito Santo, Espírito Santo/Brasil

\author{
Cláudia Porto do Nascimento \\ ORCID: http://orcid.org/0000-0003-2450-2729 \\ Psicóloga Clínica (CRP 16/5162), Espírito Santo/Brasil
}

Declaração de Direito Autoral

A submissão de originais para este periódico implica na transferência, pelos autores, dos direitos de publicação impressa e digital. Os direitos autorais para os artigos publicados são do autor, com direitos do periódico sobre a primeira publicação. Os autores somente poderão utilizar os mesmos resultados em outras publicações indicando claramente este periódico como o meio da publicação original. Em virtude de sermos um periódico de acesso aberto, permite-se o uso gratuito dos artigos em aplicações educacionais e científicas desde que citada a fonte conforme a licença CC-BY da Creative Commons.

\section{Resumo}

O ensino superior é contexto no qual fatores ansiogênicos e estressores podem estar presentes. Assim, este estudo objetivou avaliar os níveis de estresse e de ansiedade antes e após a participação de universitários em oficinas de controle de ansiedade e de enfrentamento do estresse. A proposta das oficinas, delineada a partir dos princípios da clínica analítico-comportamental, contou com 8 sessões, com 2 horas de duração cada. Após darem seu consentimento por escrito, os 11 universitários participantes (em sua maioria jovens, em seu primeiro curso superior) preencheram, na 1ํㅗㅇ sessão de coleta de dados: 1) Questionário de dados sociodemográficos; 2) Inventário de Sintomas de Stress para Adultos (ISSL); e 3) Inventário de Ansiedade de Beck (BAI). Após a participação nas oficinas, foi realizada a $2^{\mathrm{a}}$ sessão de coleta de dados, com aplicação do ISSL e do BAI e de um questionário de satisfação do usuário. Os resultados evidenciaram que 90,9\% dos participantes apresentaram estresse na $1^{\mathrm{a}}$ avaliação, todos na fase de resistência, sendo que esse percentual foi reduzido para $72,7 \%$ na $2^{\text {a }}$ avaliação; $72,75 \%$ dos participantes apresentaram ansiedade tanto na $1^{\mathrm{a}}$ quanto na $2^{\mathrm{a}}$ avaliação, embora com redução da gravidade da ansiedade para alguns participantes. As oficinas foram positivamente avaliadas em função do autoconhecimento e autocontrole desenvolvidos, bem como pelo apoio social recebido pelos participantes. Discute-se as implicações dos resultados para a oferta de intervenções voltadas ao manejo e autorregulação das emoções na população universitária. 
Palavras-chaves: Universitários; Adaptação acadêmica; Ansiedade; Estresse; Estratégias de enfrentamento.

\title{
Resumen
}

La enseñanza superior es un contexto en el cual factores ansiogénicos y estresores pueden estar presentes. Este estudio objetivó evaluar los niveles de estrés y ansiedad antes y después de la participación de universitarios en talleres de control de ansiedad y enfrentamiento del estrés. La propuesta, delineada a partir de los principios de la clínica analítico-conductual, contó con 8 sesiones, con 2 horas de duración cada una. Después de dar su consentimiento por escrito, los 11 universitarios participantes (en su mayoría jóvenes, en su primer curso superior) llenaron, en la $1^{\mathrm{a}}$ sesión de recolección de datos: 1) Cuestionario de datos sociodemográficos; 2) Inventario de Síntomas de Estrés para Adultos (ISSL); y 3) Inventario de Ansiedad de Beck (BAI). Después de la participación en los talleres, se realizó la $2^{\text {a }}$ sesión de recolección de datos, con aplicación del ISSL y del BAI y de un cuestionario de satisfacción del usuario. Los resultados evidenciaron que el 90,9\% de los participantes presentaron estrés en la $1^{\underline{a}}$ evaluación, todos en la fase de resistencia, siendo que ese porcentaje se redujo al 72,7\% en la $2^{\mathrm{a}}$ evaluación; el 72,75\% presentaron ansiedad tanto en la $1^{\mathrm{a}}$ y en la $2^{\text {a }}$ evaluación, aunque con reducción de la gravedad de la ansiedad para algunos participantes. Los talleres fueron positivamente evaluados en función del autoconocimiento y autocontrol desarrollados, así como por el apoyo social recibido. Se discuten las implicaciones de los resultados para la oferta de intervenciones dirigidas al manejo y autorregulación de las emociones en la población universitaria.

Palabras claves: Universitarios; Adaptación académica; Ansiedad; Estrés; Estrategias de enfrentamiento.

\begin{abstract}
College is a context in which anxiety and stressful factors may be present. Thus, this study aimed to evaluate the levels of stress and anxiety before and after the participation of university students in anxiety control and stress coping workshops. The proposal of the workshops, outlined from the principles of the analytical-behavioral clinic, counted on 8 sessions, each lasting 2 hours. After giving their written consent, the 11 participating university students (mostly young people, in their first university course) filled in the 1st session of data collection: 1) Questionnaire of sociodemographic data; 2) Inventory of Stress Symptoms for Adults (ISSL); and 3) Beck Anxiety Inventory (BAI). After the participation in the workshops, the 2nd session of data collection was carried out, with ISSL and BAI application and a user satisfaction questionnaire. The results showed that $90.9 \%$ of the participants presented stress in the 1 st evaluation, all in the resistance phase, and this percentage was reduced to $72.7 \%$ in the 2 nd evaluation; $72.75 \%$ of the participants presented anxiety in both the 1st and 2nd evaluation, although with reduction of anxiety severity for some participants in the 2 nd evaluation. The workshops were positively evaluated due to the selfknowledge and self-control developed, as well as the social support received by the participants. It discusses the implications of the results for the provision of interventions aimed at the management and self-regulation of emotions in the university population.
\end{abstract}

Keywords: University; Academic adaptation; Anxiety; Stress; Coping strategies.

\section{Introdução}

O ingresso no ensino superior é caracterizado por mudanças nos âmbitos pessoal, social e acadêmico, exigindo do universitário várias adaptações, para o melhor desempenho de seu papel de estudante nesse novo contexto cercado de expectativas 
(Bonifácio, Silva, Montesano, \& Padovani, 2011; Moreno, \& Soares, 2014; Porto, \& Soares, 2017; Soares et al., 2014; Teixeira, Castro, \& Zoltowski, 2012). A identificação e a satisfação do estudante com a carreira escolhida promovem maior engajamento com o curso, ajudam na superação das dificuldades encontradas na trajetória do ensino superior e promovem maior bem-estar psicológico, de acordo com a literatura da área (Bardagi, Lassance, \& Paradiso, 2003; Buscacio, \& Soares, 2017).

$\mathrm{Na}$ transição para a universidade, o aluno depara-se com uma realidade diferente da vivenciada ao longo do Ensino Médio, sendo necessário o desenvolvimento de diversas competências sociais fundamentais para o sucesso acadêmico, formação e promoção da carreira desse acadêmico (Rosário et al., 2010; Teixeira, \& Costa, 2017). A literatura aponta que fatores como apoio emocional da família, o fortalecimento das relações sociais com professores e demais alunos, a ampliação de estratégias para um bom rendimento escolar (e.g., melhoria da produção escrita e gestão do tempo de estudo), o desenvolvimento de competências, dentre outros, contribuem para a integração e permanência do acadêmico na universidade (Basso, Graf, Lima, Schmidt, \& Bardagi, 2013; Lopes, Dascanio, Ferreira, Del Prette, \& Del Prette, 2017; Oliveira, Carlotto, Teixeira, \& Dias, 2016). A ausência desses fatores de proteção pode contribuir para o aumento e desenvolvimento de quadros de ansiedade e estresse entre os estudantes universitários.

A ansiedade e o estresse são reações adaptativas frente a eventos que representam mudanças ou ameaças na vida dos sujeitos e, em geral, são quadros temporários; mas quando se perpetuam, podem se tornar prejudiciais, trazendo consequências negativas para a qualidade de vida e desempenho profissional dos indivíduos (Ferreira et al., 2009; Lantyer, Varanda, Souza, Padovani, \& Viana, 2016). A ansiedade é composta por um conjunto de reações físicas e psicológicas (e.g., taquicardia, sudorese, preocupações antecipatórias e medo), caracterizada por um estado de alerta frente a um perigo potencial, logo, importante para preparar o organismo à ação (Bravim, \& Farias, 2011). Por outro lado, a ansiedade pode se tornar prejudicial quando passa a interferir de forma exacerbada na vida do indivíduo e, no contexto acadêmico, pode gerar desempenho precário nas tarefas, acarretando reprovações e até mesmo evasão escolar (Ambiel, Santos, \& Dalbosco, 2016; Cruz, Pinto, Almeida, \& Aleluia, 2010; Morais, Mascarenhas, \& Ribeiro, 2010).

Já estresse, por sua vez, é um conjunto de respostas que ocorre quando os indivíduos passam por situações que desafiam seus limites ou recursos psicológicos e, quanto mais as situações são interpretadas como incontroláveis ou imprevisíveis, maiores são as chances de tais eventos serem percebidos como estressantes (Bardagi, \& Hutz, 2011). Atividades rotineiras do ensino superior, como a realização de provas e exames escritos, bem como a carga horária excessiva e a dificuldade de organização ou conciliação com outros aspectos da vida, como as interações sociais e o lazer, podem ser geradoras de ansiedade e estresse entre universitários (Corral-Mulato, Baldissera, Santos, Philbert, \& Bueno, 2011; García-Ros, Pérez-Gonzaléz, Pérez-Blasco, \& Natividad, 2012; Karino, \& Laros, 2014; Moreira, Vasconcellos, \& Heath, 2015; Piemontesi, Heredia, Furlan, Sánchez-Rosas, \& Martínez, 2012). Assim, o contexto acadêmico apresenta inúmeros desafios e, caso o estudante não possua repertórios de comportamentos adequados para lidar com tais desafios poderá ter sua saúde e seu bem-estar afetados (Ramos, Enumo, \& Paula, 2015). Daí ser importante favorecer, nesse contexto, o desenvolvimento de estratégias de enfrentamento (coping) dos estressores.

Os achados da literatura apontam algumas respostas de enfrentamento eficazes adotadas por estudantes para lidar com o estresse da vida acadêmica, dentre elas a valorização dos relacionamentos interpessoais, o equilíbrio entre o estudo, lazer e organização do tempo, os cuidados com a saúde, 
alimentação e sono, a prática de atividades físicas e a religiosidade (Alves, 2010; Oliveira, Carlotto, Vasconcelos, \& Dias, 2014). Não há uma estratégia de coping considerada mais vantajosa em relação às outras, pois os benefícios resultantes do uso flexível das diversas estratégias exercem diferentes impactos na qualidade de vida do estudante, permitindo o desenvolvimento de seus recursos pessoais, maior autoconfiança e construção de redes de suporte social, o que contribui para a diminuição dos indicadores de estresse (Aragão, Vieira, Alves, \& Santos, 2009; Casari, Anglada, \& Daher, 2014; Hirsch et al., 2015).

A intensidade e a frequência com que o universitário é exposto a eventos ansiosos e estressores, bem como a ausência de repertórios de enfrentamento eficazes e voltados para a resolução ativa dos problemas do cotidiano podem impactar negativamente na qualidade da aprendizagem e dos processos cognitivos a ela relacionados (Borine, Wanderley, \& Bassitt, 2015; Melo, Peixoto, Oliveira, \& Bizarro, 2012). Podem também contribuir para o desengajamento em relação às demandas escolares (Skinner, Pitzer, \& Brule, 2014), aumentar a retenção (Pereira, Carneiro, Brasil, \& Corassa, 2014) e a evasão (Cunha, \& Morosini, 2013) escolares. Assim, diante das potenciais fontes de ansiedade e estresse psicológico com as quais o estudante pode se deparar na universidade, é importante oferecer serviços psicológicos voltados para a diminuição da evasão escolar e dos problemas de ajustamento acadêmico, assim como para a prevenção ao surgimento ou agravamento de quadros psicopatológicos, como depressão, ansiedade e estresse, comumente associados a dificuldades de adaptação e insucesso acadêmico (Bardagi, \& Hutz, 2005; Bisinoto, Marinho, \& Almeida, 2011; Padovani et al., 2014; Santos, Souto, Silveira, Perrone, \& Dias, 2015; Liébana-Presa et al., 2014). Nesse contexto, é possível acolher as demandas que surgem dessas vivências acadêmicas, prevenir quadros de adoecimento e contribuir para o desenvolvimento de habilidades de autorregulação (Amaral et al., 2012; Garcia,
Bolsoni-Silva, \& Nobile, 2015; Zeferino et al., 2015).

Intervenções individuais e em grupo, no referencial da abordagem analíticocomportamental e cognitivo-comportamental, têm se mostrado eficazes para o tratamento dos transtornos de estresse e ansiedade, proporcionando resultados terapêuticos positivos em curto e médio prazos para a população universitária (Chagas, Guilherme, \& Moriyama, 2013; Furlan, 2013; Oliveira, Dias, \& Piccoloto, 2013). Nesse contexto, destacam-se as intervenções para a promoção de competências sociais em universitários (Bolsoni-Silva, Leme, Lima, Costa-Júnior, \& Correia, 2009; Del Prette, \& Del Prette, 2003; Ferreira, Oliveira, \& Vandenberghe, 2014; Lopes et al., 2017; Pureza, Rusch, Wagner, \& Oliveira, 2012), dada a sua relevância para a adaptação de estudantes ao ensino superior (Gerk, \& Cunha, 2006). As competências sociais podem ser definidas como a qualificação/adjetivação de repertórios operantes, sobretudo verbais, que aumentam a probabilidade de resolução de problemas de natureza social isto é, produzem reforço ao comportamento eficaz emitido, reduzindo o registro de consequências aversivas para os demais envolvidos, tendo em vista a promoção de práticas culturais reforçadoras (BolsoniSilva, \& Carrara, 2010; Guilhardi, 2012).

Este trabalho descreve uma proposta de Oficina de Controle da Ansiedade e Enfrentamento do Estresse realizada com universitários e baseada nos princípios da clínica comportamental (Borges, \& Cassas, 2012). Para o alcance dos objetivos da oficina foram utilizadas, dentre outras atividades, técnicas analítico-comportamentais relacionadas aos comportamentos-alvo a serem trabalhados. Visando o controle do estresse e da ansiedade, é preciso, muitas vezes, manejar os respondentes eliciados pelas situações aversivas ou ameaçadoras. Assim, as técnicas de relaxamento podem ser úteis para esse manejo. A técnica de Relaxamento Passivo (Vera, \& Vila, 1996), por exemplo, consiste basicamente na concentração da 
atenção em cada membro do corpo, separadamente e no relaxamento que se produz, passo a passo, nesses membros, a partir das indicações verbais dadas pelo terapeuta, devendo ser conduzida em ambiente apropriado: com redução da iluminação e estimulação sonora externa e local apropriado para que os participantes possam ficar deitados em posição confortável.

Além de controlar os respondentes eliciados em situações de estresse e ansiedade, é necessário instalar novos operantes para que os indivíduos tenham mais competências para lidar com diversas situações no seu dia a dia. Assim, por meio do Ensaio Comportamental é possível aprimorar operantes já existentes no repertório comportamental do indivíduo ou instalar novos comportamentos. Nessa técnica, são simuladas situações reais (cenas) de interação da vida da pessoa nas quais ela apresenta dificuldades (Otero, 2004). E os participantes (no caso de intervenções em grupo) e os terapeutas dão feedback sobre o desempenho, sugerindo alternativas para lidar com a situação. Com essa finalidade, a pessoa repete a cena, incorporando as sugestões do grupo, quantas vezes forem necessárias até que seja alcançado o desempenho satisfatório (Otero, 2004). Também é usual, no contexto da clínica comportamental individual, ou em grupo, o uso de atividades para casa, a fim de favorecerem o acesso aos comportamentos necessários à vida diária do cliente, bem como para aumentar o seu autoconhecimento por meio da auto-observação e da autodescrição (Martim, \& Silveira, 2017).

Além da descrição da metodologia de intervenção utilizada na Oficina de Controle da Ansiedade e Enfrentamento do Estresse, este trabalho teve como objetivos: avaliar os níveis de estresse e de ansiedade em universitários antes e após sua participação na oficina; avaliar a satisfação dos estudantes quanto a sua participação na oficina $e$ identificar as atividades que, na percepção dos participantes, foram mais eficazes para auxiliá-los a controlar o estresse e a ansiedade.

\section{Metodologia \\ Procedimento de coleta de dados e aspectos éticos}

A coleta de dados iniciou-se após a aprovação da pesquisa pelo Comitê de Ética em Pesquisas com Seres Humanos da Universidade Federal do Espírito Santo (Parecer $\mathrm{n}^{\mathrm{o}}$ 1.345.372), sendo realizada por uma bolsista de iniciação científica, graduanda em Psicologia, vinculada ao Projeto de Pesquisa "Estresse, ansiedade e estratégias de enfrentamento em contexto universitário: avaliação e intervenção". Os participantes foram recrutados no $1^{\mathrm{o}}$ dia de duas Oficinas de Controle de Ansiedade e Enfrentamento do Estresse (realizadas no âmbito do Projeto de Extensão: "Serviço de Atenção Psicológica ao Graduando da Universidade Federal do Espírito Santo - Sapsig"), uma iniciada em Maio de 2016 (denominada Oficina A) e a outra em Junho de 2016 (denominada Oficina B). Os procedimentos de coleta de dados foram os mesmos para os participantes de ambas as oficinas.

Após a explicação dos procedimentos para a coleta de dados, os participantes assinaram o Termo de Consentimento Livre e Esclarecido (TCLE) e preencheram, na $1^{\text {a }}$ sessão de coleta de dados (pré-teste), um Questionário de Dados Sociodemográficos, um Instrumento de Triagem Psicológica (Jardim, \& Ramos, 2017), o Inventário de Sintomas de Stress para Adultos de Lipp ISSL (Lipp, 2005) e o Inventário de Ansiedade Beck - BAI (Cunha, 2001). Esses dois últimos instrumentos de uso restrito para psicólogos, condição que foi respeitada na presente pesquisa. Após o término das 8 sessões de cada uma das oficinas, os participantes foram novamente abordados $\left(2^{\mathrm{a}}\right.$ sessão de coleta de dados, pós-teste) e preencheram pela segunda vez, o ISSL e o BAI, além de um Inventário de Satisfação do Usuário (adaptado pelos autores da presente pesquisa do original de Eyberg, 1993). A devolutiva dos resultados obtidos com os instrumentos psicológicos foi realizada de duas maneiras: (1) o resultado da $1^{\underline{a}}$ avaliação 
do ISSL e do BAI foi devolvido individualmente a cada participante, ao final de uma das sessões da Oficina e (2) o resultado da $2^{\text {a }}$ avaliação do ISSL e BAI foi devolvido por e-mail a cada um dos participantes, após o término da Oficina. Em ambos os casos, foi entregue um documento, por escrito, que continha o escore do participante, seu nível de estresse e de ansiedade, bem como sugestões de como proceder para melhorar tais indicadores emocionais.

\section{Participantes}

Foram critérios de inclusão na amostra: (1) estar inscrito em uma das Oficinas de Controle de Ansiedade e Enfrentamento do Estresse do Projeto Sapsig; (2) desejar participar da pesquisa (o participante poderia frequentar a Oficina sem aderir à proposta da pesquisa); (3) ter frequentando $75 \%$ da carga horária da Oficina (isto é, não ter faltado a mais de duas sessões) e (4) estar presente no último dia da Oficina, para participar da coleta pós-teste. Assim, da Oficina A participaram 12 universitários, no total, mas somente 8 atenderam aos critérios de inclusão e da Oficina B, participaram 8 estudantes, no total, mas somente 3 atenderam aos critérios de inclusão. Logo, a amostra final (pré e pósteste) foi composta de 11 universitários. Os participantes da Oficina A foram numerados de P1 a P8 e os participantes da Oficina B, de P9 a P11 para fins de descrição dos resultados.

\section{Instrumentos e materiais}

O Questionário de Dados Sociodemográficos (QDS), desenvolvido pelos autores dessa pesquisa, continha questões relativas à idade, renda familiar, curso, horários de aula e de trabalho (questões abertas), bem como os níveis de identificação e satisfação dos estudantes com seu curso de graduação (questões fechadas). Já o Instrumento de Triagem Psicológica (ITP), especialmente elaborado para uso nas atividades do Projeto de Extensão (Jardim, \& Ramos, 2017), tinha por objetivo, a partir da descrição de uma queixa, avaliar cinco dimensões para a direção do tratamento, conforme Beutler e Clarkin (2014): severidade e complexidade da queixa, motivação e recursos para o tratamento e estilos de coping (enfrentamento). O ITP conta com 20 afirmações em escala likert de 1 a 4 pontos (sendo 1: nunca e 4: sempre), distribuídas nessas cinco dimensões.

O Inventário de Sintomas de Stress para Adultos de Lipp - ISSL (Lipp, 2005), por sua vez, é um instrumento que fornece uma medida objetiva da sintomatologia do estresse, classificando a presença de estresse em quatro fases: (1) a primeira fase do estresse é denominada de "alerta" e pode ser compreendida como a fase do estresse quando o indivíduo se prepara para a ação; (2) a segunda fase é denominada de "resistência" e se caracteriza pela vivência prolongada dos eventos estressores, quando o organismo entra em ação para impedir o desgaste de energia e tentar reestabelecer o equilíbrio interior; (3) a terceira fase, denominada de "quaseexaustão", ocorre quando a tensão excede o limite do gerenciável pelo indivíduo, quando começam a surgir doenças ligadas ao estresse; e (4) a quarta fase é denominada de "exaustão" que pode ser compreendida como a fase mais negativa do estresse, quando o desequilíbrio é marcante e o indivíduo não consegue se concentrar ou trabalhar com eficiência. Além disso, o instrumento avalia a predominância de sintomas físicos ou psicológicos do estresse.

Já o Inventário de Ansiedade Beck BAI (Cunha, 2001) avalia a ansiedade do indivíduo por meio de um questionário de autorrelato, contendo 21 questões que expressam sintomas comuns da ansiedade que o indivíduo pode ter experimentado na última semana, incluindo o dia da aplicação. Pode-se assinalar, em cada questão, uma dentre quatro possíveis respostas (absolutamente não, levemente, moderadamente e gravemente) que servem para identificar o nível de ansiedade em que o participante se encontra (mínimo, leve, moderado ou grave). Por fim, o 
Inventário de Satisfação do Usuário (adaptado pelos autores da presente pesquisa do original de Eyberg, 1993) avaliou a percepção dos participantes a respeito do quanto a Oficina auxiliou na aprendizagem de estratégias de enfrentamento do estresse e da ansiedade, bem como quais foram as atividades avaliadas como mais importantes para auxiliá-los no controle desses estados emocionais.

Além desses instrumentos, foram utilizados os seguintes materiais para a realização de algumas das atividades das oficinas: cartolinas, pincéis, folhas de papel A4, canetas e o Jogo "Imagem e Ação" da Grow®.

\section{Análise dos dados}

A correção dos dados obtidos nas duas aplicações do ISSL e do BAI foi realizada de acordo com os manuais de cada instrumento (Lipp, 2005 e Cunha, 2001, respectivamente), e os dados sociodemográficos dos participantes foram organizados em planilhas Excel®, a fim de serem calculadas as estatísticas descritivas. O perfil da amostra foi descrito segundo as variáveis: sexo, idade, curso, período, área de conhecimento, dentre outros. Esses dados foram analisados a partir das funções estatísticas: média, mediana, moda e desvio padrão. Dado o número reduzido de participantes, não foi possível utilizar técnicas de análise estatística inferencial para a comparação dos escores antes e após a participação nas oficinas.

\section{Contexto e proposta das oficinas de controle da ansiedade e enfrentamento do estresse}

As Oficinas são desenvolvidas no âmbito do Projeto de Extensão Sapsig, integrando pesquisa, extensão e ensino. A divulgação das oficinas é feita em parceria com a Pró-Reitoria de Assuntos Estudantis e Cidadania da universidade que envia, um $e$ mail, aos estudantes assistidos em seus programas informações pertinentes sobre as Oficinas. Os interessados inscrevem-se a partir de um link e são convidados a delas participarem por ordem de inscrição.

Cada oficina é desenvolvida em 8 sessões no total, sendo uma sessão por semana, com duração de 2 horas cada, com no máximo 12 participantes. Os encontros das oficinas acontecem em uma sala de grupo, com colchões e almofadas dispostos no chão, no Núcleo de Psicologia Aplicada da universidade. As sessões das oficinas são conduzidas por duplas de terapeutas, graduandos em Psicologia, devidamente capacitados. Ao ingressarem no Projeto de Extensão, os graduandos em Psicologia participam de um curso de 20 horas, no qual são abordados os fundamentos da clínica analítico-comportamental (Borges, \& Cassas, 2012), referencial teórico que embasa as intervenções do Projeto, bem como são abordadas as metodologias de intervenção utilizadas no Projeto. Além disso, semanalmente, os alunos-terapeutas recebem supervisão das atividades desenvolvidas.

No primeiro encontro do grupo, antes do início das Oficinas propriamente ditas, após a apresentação dos participantes, das terapeutas e da proposta da oficina, cada estudante respondeu o QDS e o ITP (Jardim, $\&$ Ramos, 2017). Nesse primeiro encontro, os participantes também foram instruídos a descrever verbalmente o motivo que os fizeram procurar a Oficina. Após o término do primeiro encontro, foi realizada uma análise do perfil do estudante, tendo em vista a proposta da Oficina, isto é, se suas demandas se relacionavam com problemas ligados ao estresse e ansiedade e se suas queixas podiam ser atendidas na Oficina. Em caso de o estudante não ser adequado ao perfil das Oficinas, ele era encaminhado para outras modalidades desse programa (e.g., Orientação aos Estudos; Habilidades Sociais) ou para psicoterapia individual, todas oferecidas no âmbito do mesmo Projeto de Extensão. Esse procedimento adotado no encontro inicial foi aplicado em ambas as oficinas, A e B.

As duas oficinas de Controle da Ansiedade e Enfrentamento do Estresse aqui 
analisadas contaram com algumas atividades diferentes em função das características de cada grupo, tendo sido conduzidas por duplas diferentes de terapeutas, todas mulheres. Assim, são descritas, a seguir, as atividades desenvolvidas em cada um dos encontros das oficinas.

1ํㅗㅁ Sessão (Oficina A e B) - Nessa sessão, foi realizada a acolhida dos participantes, por meio de verbalizações dos terapeutas que expressavam a importância dos universitários terem buscado ajuda e da explicitação dos aspectos a serem trabalhados nas oficinas. Em seguida, foi realizada uma dinâmica de apresentação (adaptada de Del Prette, \& Del Prette, 2001) na qual os participantes, divididos em duplas, deveriam conhecer aspectos do colega: local onde morava, curso que realizava, atividades de lazer, dentre outras informações. Em seguida, cada participante apresentava seu colega para todo o grupo. Na sequência, foi conduzida uma dinâmica, com auxílio de cartolinas (inicialmente em branco) nas quais os participantes, divididos em pequenos grupos, escreviam o que acreditavam ser as diferenças entre o estresse e a ansiedade. Posteriormente, cada grupo apresentava seu cartaz e o conteúdo era discutido com todo o grupo, com a mediação das terapeutas. Por fim, para os participantes que aceitaram participar da pesquisa, foi feita a coleta de dados com assinatura do TCLE e os participantes foram submetidos aos instrumentos psicológicos ISSL (Lipp, 2005) e BAI (Cunha, 2001).

2a Sessão (Oficina A) - Inicialmente, foi realizada uma discussão com os participantes sobre o que eles consideravam ser as principais fontes do estresse e da ansiedade que vivenciavam, tendo sido relatados principalmente cobranças e exigências relacionadas ao estudo e desempenho acadêmico no ensino superior. Em seguida, foi conduzida dinâmica, com auxílio de cartolinas, nas quais, compondo pequenos grupos, os participantes foram estimulados a descrever os principais sintomas físicos percebidos em momentos de estresse e ansiedade, com a finalidade de favorecer-lhes a auto-observação dos respondentes sentidos nesses momentos. Em seguida, cada grupo relatava a tarefa para todos os demais grupos. Por fim, foi solicitado aos participantes, como atividade para casa, que registrassem, diariamente, até o próximo encontro da Oficina, três eventos positivos que haviam acontecido nesse período. Logo, essa atividade tinha por objetivo colocá-los sob o controle de potenciais eventos com função reforçadora e não somente dos aversivos experimentados no dia a dia.

3- Sessão (Oficina A) - Inicialmente, foi conduzida discussão sobre a atividade que realizaram em casa, levantando-se as impressões dos participantes sobre sua realização, ou as dificuldades para realizá-la. Também foram discutidos eventuais benefícios de se estar atento a eventos com função positivamente reforçadora. A seguir, foram explicados os fundamentos da técnica de Relaxamento de Passivo (Vera, \& Vila, 1996), passando-se, na sequência, à sua aplicação, conduzida pelas terapeutas, com a devida adequação do ambiente para a prática: redução da iluminação da sala e participantes deitados em colchões apropriados. Após finalização da técnica, foram discutidas as dificuldades encontradas pelos participantes, bem como os benefícios e a importância da prática dessa técnica como ferramenta auxiliar no controle do estresse e da ansiedade.

$4^{\mathrm{a}}$ Sessão (Oficina A) - Essa sessão foi inteiramente dedicada à realização da Técnica do Ensaio Comportamental (Otero, 2004), já descrita anteriormente. Inicialmente, foram explicados os fundamentos da técnica, bem como suas possibilidades de aplicação. Em seguida, foi solicitado aos participantes que relatassem alguma situação recente em que tivessem experienciado momentos de estresse e ansiedade, e a partir das situações relatadas foram realizados os ensaios comportamentais em duplas, até que todas as duplas fossem contempladas. Não havendo tempo para discussão sobre a técnica, a oficina foi encerrada. 
5- Sessão (Oficina A) - Inicialmente, foi retomada a discussão dos resultados do Ensaio Comportamental conduzido na sessão anterior; em seguida, foi discutida com o grupo a importância da realização de atividades físicas, da boa alimentação e da vivência de emoções positivas para a prevenção da ansiedade e do estresse, conforme indicado por Alves (2010) e Oliveira et al. (2014). Por fim, foi aplicada novamente a técnica de Relaxamento Passivo (Vera, \& Vila, 1996) e feita a devolutiva, individual, dos resultados de estresse $\mathrm{e}$ ansiedade a partir dos instrumentos aplicados na $1^{\underline{a}}$ avaliação (pré-teste).

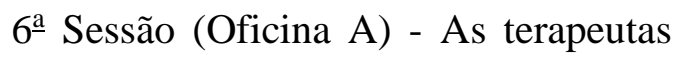
apresentaram frases pré-selecionadas de possíveis comportamentos verbais privados (pensamentos) que podem ocorrer em momentos de estresse e ansiedade (e.g., "se cometer um erro, fracassarei!", "não posso decepcionar as pessoas que amo"), e, na sequência, solicitaram aos participantes que selecionassem as autofalas relacionadas às suas vivências. Em seguida, as autofalas foram discutidas, tendo em vista a proposição de formas alternativas de se descrever nas situações colocadas em questão, pelos participantes.

7ª Sessão (Oficina A) - Inicialmente, foi realizada a dinâmica "Existem outras maneiras?" (disponível em: http://www.kombo.com.br/materiais-rh/, com adaptações), que consistia em tentar passar uma bola entre todos os participantes, no menor período de tempo possível. Em seguida, eram discutidas estratégias para otimizar o tempo, assim como a importância do autoconhecimento para o manejo de tempo. Por fim, foi discutido um texto sobre Princípios de Manejo e Controle de Tempo (disponível em: http://psicotemaesbf.blogspot.com.br/2006/12/princpios-dagesto-do-tempo.html, com adaptações).

8ª Sessão (Oficina A) - As terapeutas propuseram uma dinâmica de avaliação da oficina, na qual os participantes eram solicitados a verbalizar suas percepções positivas ou negativas sobre a Oficina. Em seguida, os participantes preencheram o Inventário de Satisfação do Usuário (adaptado pelos autores da presente pesquisa do original de Eyberg, 1993) e responderam novamente ao ISSL (Lipp, 2005) e ao BAI (Cunha, 2001) - pós-teste. Na sequência, foi proposta uma atividade lúdica de encerramento aos participantes (Jogo "Imagem e Ação" da Grow $($ ), seguido de confraternização do grupo com um lanche. Por fim, foram entregues os certificados de participação.

A seguir, são descritas as atividades da Oficina B, a partir de sua $2^{2}$ Sessão.

2ª Sessão (Oficina B) - Inicialmente, foi conduzida uma dinâmica na qual os participantes selecionaram palavras atribuídas ao estresse e à ansiedade, dentre as colocadas nos cartazes elaborados na sessão anterior. Então, foram solicitados a descrever a relação entre a palavra escolhida e os eventos vivenciados no dia a dia. Após, as terapeutas promoveram uma discussão com os participantes sobre os componentes da ansiedade e do estresse, englobando aspectos do comportamento operante e respondente, conforme relato dos participantes na primeira dinâmica realizada nessa sessão.

3모 Sessão (Oficina B) - Nessa sessão, foi aplicada a técnica de Relaxamento de Passivo (Vera, \& Vila, 1996), precedida da explicação sobre seus fundamentos e procedimentos. Após sua aplicação, foram discutidas as dificuldades encontradas pelos participantes, bem como benefícios e importância da prática dessa técnica como ferramenta auxiliar no controle do estresse e da ansiedade. Na sequência, foi realizada a devolução dos resultados de estresse e ansiedade investigados na $1^{\underline{a}}$ avaliação (préteste). Como atividade de casa, foi solicitada aos participantes a prática da técnica de Relaxamento, com auxílio de áudio gravado (elaboração própria) e enviado por e-mail aos participantes da Oficina.

4- Sessão (Oficina B) - Essa sessão foi dedicada à discussão sobre a temática das 
competências sociais (Bolsoni-Silva, \& Carrara, 2010; Guilhardi, 2012), que foi referida pelos participantes na atividade dos cartazes, conduzida na $2^{\mathrm{a}}$ sessão. A partir dessa atividade, foi possível perceber que muitas das situações de estresse e ansiedade vividas pelos participantes estavam relacionadas ao déficit de repertório para interações sociais. Assim, foi conduzida uma discussão inicial com o grupo sobre o conceito de competências sociais e suas relações com estados emocionais de estresse e ansiedade. Como tarefa de casa foi proposto aos participantes que observassem situações nas quais se comportaram de forma socialmente habilidosa durante a semana.

5- Sessão (Oficina B) - Inicialmente, foi avaliada e discutida a atividade realizada em casa, tendo em vista a identificação de possíveis comportamentos socialmente habilidosos pelos participantes. Em seguida, foi feita uma explanação sobre os comportamentos avaliados funcionalmente como "assertivos" ou "inassertivos", conforme apontado por Guilhardi (2012). Na sequência, foi aplicada a técnica do Ensaio Comportamental (Otero, 2004) de situações vivenciadas pelos participantes que requeriam competências sociais. Essa atividade foi conduzida em duplas. Então, foram instruídos a fazê-la, como tarefa de casa.
6- Sessão (Oficina B) - Foi proposta, pelas terapeutas, a realização da mesma atividade conduzida na $6^{\underline{a}}$ sessão da Oficina A, sobre as autofalas. Já na $7^{\mathrm{a}}$ sessão foi aplicada novamente a técnica de Relaxamento de Passivo, seguida da discussão da experiência com o grupo e de seus progressos em alcançar estados mais profundos de relaxamento. $\mathrm{Na} 8^{\mathrm{a}}$ e última sessão da Oficina $B$, foi executada a mesma programação descrita no último dia da Oficina A, à exceção da realização da atividade lúdica.

\section{Resultados \\ Caracterização dos participantes, identificação e satisfação com o curso}

Em relação aos dados sociodemográficos dos participantes, $45,45 \%$ eram do sexo feminino $(\mathrm{N}=5)$ e $54,54 \%$ do sexo masculino $(\mathrm{N}=6)$; a idade média foi de 22,5 anos $(\mathrm{DP}=3,83)$; a renda média foi de $\mathrm{R} \$$ 2.716,25 ( $\mathrm{DP}=2.625,70)$; sendo que $81,81 \%$ $(\mathrm{N}=9)$ dos participantes recebiam algum tipo de auxílio ou bolsa, e $72,72 \%(\mathrm{~N}=8)$ não trabalhavam. A maioria dos estudantes residia com a família $(\mathrm{N}=8 ; 72,72 \%)$, o restante morava em república $(\mathrm{N}=2 ; 18,18 \%)$ ou sozinho $(\mathrm{N}=1 ; 9,09)$.

Tabela 1.

Caracterização dos participantes em termos de sexo, idade, curso, período e turno $(N=11)$ - QDS

\begin{tabular}{lccccc}
\hline Participante & Sexo & Idade & Curso & Período & Turno \\
\hline P1 & M & 19 & Engenharia Elétrica & 1 & Integral \\
P2 & F & 29 & Serviço Social & 4 & Matutino \\
P3 & M & 21 & Engenharia Civil & 3 & Matutino \\
P4 & F & 24 & Nutrição & 12 & Integral \\
P5 & F & 21 & Direito & 7 & Matutino \\
P6 & F & 18 & Artes Plásticas & 1 & Vespertino \\
P7 & F & 21 & Letras & 5 & Matutino \\
P8 & M & 28 & Administração & 4 & Noturno \\
P9 & M & 20 & Engenharia Civil & 3 & Integral \\
P10 & M & 20 & Educação Física & 4 & Matutino \\
P11 & M & 27 & Ciências Contábeis & 5 & Noturno \\
\hline
\end{tabular}

Nota. $\mathrm{M}=$ masculino, $\mathrm{F}=$ feminino.

Todos os participantes estavam em seu primeiro curso superior, sendo oriundos dos cursos de Ciências Sociais Aplicadas $(\mathrm{N}=4$;
$36,36 \%)$ Engenharias $(\mathrm{N}=3 ; \quad 27,27 \%)$, Ciências Humanas $(\mathrm{N}=2 ; 18,18 \%)$ e Ciências da Saúde $(\mathrm{N}=2 ; 18,18 \%)$; cursando entre o $1^{\mathrm{o}}$ 
e o $3^{\text {o }}$ períodos $(\mathrm{N}=4 ; 36,36 \%)$, entre o $4^{\underline{o}}$ e $6^{\underline{o}}$ períodos $(\mathrm{N}=5 ; 45,45 \%)$ e do $7^{\text {o }}$ período em diante $(\mathrm{N}=2 ; 18,18 \%)$. A maior parte dos universitários estudava no turno matutino $(\mathrm{N}=5 ; 45,45 \%)$, seguido de período integral $(\mathrm{N}=3 ; 27,27 \%)$, turno noturno $(\mathrm{N}=2 ; 18,18 \%)$ e vespertino $(\mathrm{N}=1 ; 9,09 \%)$. Alguns aspectos de caracterização de cada um dos participantes são apresentados na Tabela 1.

Em relação à avaliação do curso, a maioria dos participantes declarou se sentir muito identificado $(54,54 \%)$ e muito satisfeito $(45,45 \%)$ com o curso superior, conforme pode ser observado na Tabela 2.

Tabela 2.

Satisfação e identificação com o curso entre os universitários participantes $(N=11)-Q D S$

\begin{tabular}{ccc}
\hline Questão & Resposta & $\%$ \\
\hline \multirow{2}{*}{ O quanto você se identifica com seu } & Não me identifico nem um pouco & 18,18 \\
curso? & Me identifico um pouco & 27,27 \\
& Me identifico muito & 54,54 \\
\hline \multirow{2}{*}{ O quanto você está satisfeito com seu } & Não estou nem um pouco satisfeito & 27,27 \\
curso? & Estou um pouco satisfeito & 27,27 \\
& Estou muito satisfeito & 45,45 \\
\hline
\end{tabular}

\section{Avaliação do estresse e da ansiedade}

Em relação à avaliação de estresse, na $1^{1}$ a sessão de coleta de dados (pré-teste), 10 dentre os 11 participantes apresentaram estresse $(90,9 \%)$, todos, na fase de resistência. Já na $2^{\text {a }}$ sessão de coleta de dados (pós-teste), 8 dos participantes permaneceram com estresse $(72,7 \%)$, sendo que 7 deles permaneceram na fase de resistência e 1 passou para a fase de exaustão. A participante sem estresse (P7) permaneceu nessa condição do pré para o pós-teste e avaliou estar muito satisfeita e se identificar muito com o curso. Nos demais participantes que apresentaram estresse, a satisfação e a identificação com o curso variou. Dois participantes deixaram de apresentar estresse, e 1 participante teve seu estresse agravado do pré para o pós-teste. Observou-se que $80 \%$ dos participantes apresentaram tendência a experimentar sintomas psicológicos do estresse na $1^{\mathrm{a}}$ sessão de coleta, e $62,5 \%$ na $2^{-}$sessão de coleta. Os resultados podem ser vistos na Figura 1.

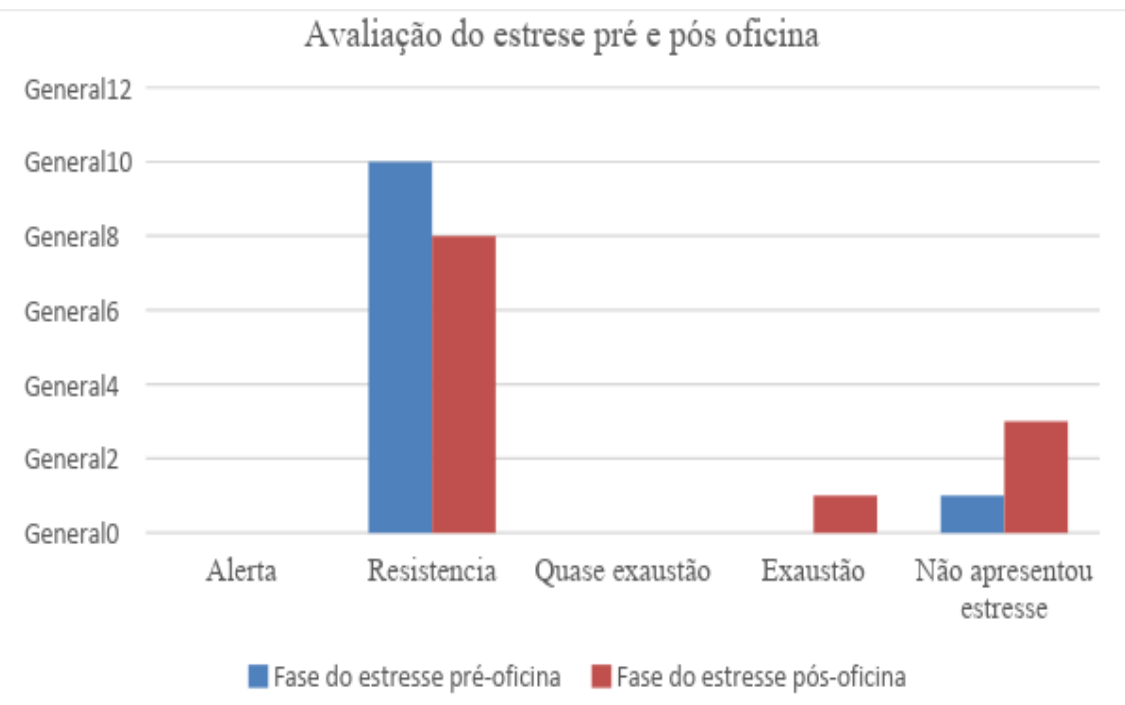

Figura 1. Avaliação do estresse antes e após a participação nas oficinas

No que se refere à avaliação da ansiedade, no pré-teste, 8 participantes apresentaram ansiedade $(72,75 \%)$, sendo que a metade deles (4 participantes) alcançaram nível leve, 3 participantes apontaram nível moderado e 1 nível grave da ansiedade. Já no 
pós-teste, 8 participantes mantiveram-se ansiosos, sendo 4 na fase leve e 4 na fase moderada. Dentre os 3 participantes que não apresentaram ansiedade na $1^{\underline{a}}$ avaliação, somente 1 informou não se identificar e não estar satisfeito com o curso. Os resultados comparativos da ansiedade podem ser observados na Figura 2.

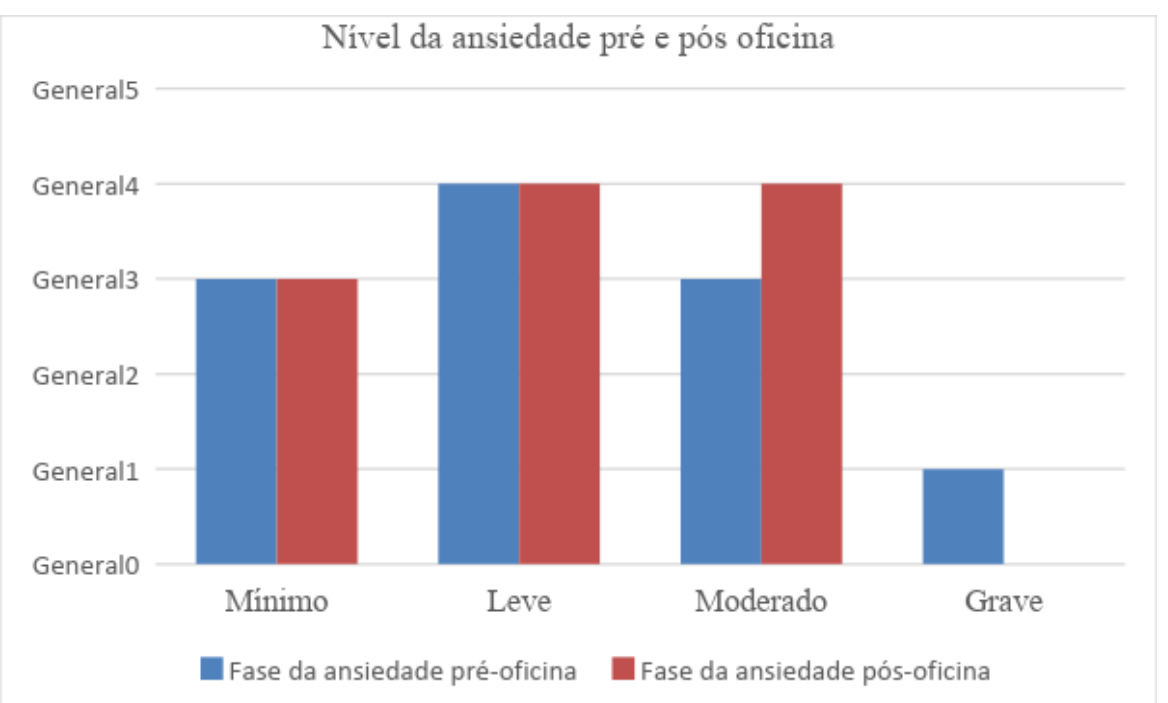

Figura 2. Nível de ansiedade antes e após a participação nas oficinas

Os resultados da avaliação de estresse e ansiedade por participante nas duas fases da pesquisa podem ser observados na Tabela 3 .

Tabela 3.

Resultados do pré e pós-teste de estresse e ansiedade por participante da Oficina de Controle de Ansiedade e Enfrentamento do Estresse $(N=11)$ - ISSL e BAI

\begin{tabular}{|c|c|c|c|c|}
\hline \multirow{2}{*}{ Participante } & \multicolumn{2}{|c|}{ Avaliação do Estresse } & \multicolumn{2}{|c|}{ Nivel de ansiedade } \\
\hline & Pré-teste & Pós-teste & Pré-teste & Pós-teste \\
\hline $\mathrm{P} 1$ & Fase de resistência & Fase de resistência & Moderado & Moderado \\
\hline $\mathrm{P} 2$ & Fase de resistência & Fase de resistência & Leve & Moderado \\
\hline P3 & Fase de resistência & Fase de exaustão & Leve & Leve \\
\hline $\mathrm{P} 4$ & Fase de resistência & Fase de resistência & Grave & Moderado \\
\hline P5 & Fase de resistência & Fase de resistência & Moderado & Leve \\
\hline P6 & Fase de resistência & Sem estresse & Leve & Mínimo \\
\hline P7 & Sem estresse & Sem estresse & Mínimo & Mínimo \\
\hline P8 & Fase de resistência & Fase de resistência & Mínimo & Leve \\
\hline P9 & Fase de resistência & Fase de resistência & Mínimo & Leve \\
\hline $\mathrm{P} 10$ & Fase de resistência & Sem estresse & Moderado & Mínimo \\
\hline $\mathrm{P} 11$ & Fase de resistência & Fase de resistência & Leve & Moderado \\
\hline
\end{tabular}

\section{Avaliação da satisfação dos participantes com a proposta da Oficina}

O questionário de satisfação do usuário foi utilizado para sistematizar uma avaliação quanto às atividades propostas nas oficinas, sugestões de aperfeiçoamento do serviço, assim como para avaliar o desempenho das terapeutas que conduziram as atividades. Por meio de uma escala Likert de 0 a 5 pontos, os
11 participantes avaliaram que aprenderam muitas coisas com o grupo (média $=4,09$ ), consideraram que obtiveram bom aproveitamento (média $=4$ ) e que se sentiram mais confiantes para lidar com o estresse e com a ansiedade após a participação no grupo (média $=3,72$ ). As atividades que os participantes avaliaram como sendo mais interessantes foram aquelas relacionadas ao autoconhecimento, autocontrole e o suporte 
social entre os participantes. A avaliação das terapeutas indicou que os participantes consideraram a atuação delas satisfatória, sobretudo devido ao domínio do conteúdo e habilidade para a condução do grupo.

\section{Discussão}

Em relação ao perfil dos participantes deste estudo, verificou-se, a predominância de uma população jovem (idade média de 22,5 anos) em seu primeiro curso superior. $\mathrm{O}$ fato de a maioria dos participantes receber algum tipo de auxílio ou bolsa relacionou-se à forma de divulgação das oficinas, feita no âmbito da Pró-Reitoria da universidade, que gerencia a distribuição de diversos auxílios e bolsas aos universitários. Em relação à proposta de cada uma das oficinas, percebeu-se, a partir da descrição da programação das sessões realizadas que na Oficina $B$ houve maior ênfase na prática da técnica de Relaxamento Passivo (Vera, \& Vila, 1996), aplicada em duas sessões, e maior ênfase na prática em casa, no intervalo entre as sessões do que na Oficina A. Além disso, a Oficina B contou com conteúdo sobre habilidades sociais (Bolsoni-Silva, \& Carrara, 2010; Guilhardi, 2012) que não ocorreu na Oficina $A$, haja vista as dificuldades nessas habilidades relatadas pelos próprios participantes do grupo. Assim, a programação das oficinas foi desenvolvida de acordo com as necessidades específicas de cada grupo de participantes.

pelos participantes nos instrumentos psicológicos padronizados (ISSL e BAI) foram verificados níveis de estresse elevados entre os participantes, se comparado com os escores da população em geral, conforme demonstram outros estudos da área (CorralMulato et al., 2011; Morais et al., 2010; Padovani et al., 2014), sendo que o estresse apresentou-se mais grave que a ansiedade na população pesquisada. Embora não se tenham dados sobre o estresse e a ansiedade dos participantes antes do ingresso no ensino superior que permitissem uma comparação de tais indicadores com aqueles obtidos nesta pesquisa, as verbalizações dos universitários durante os encontros das oficinas apontam para a importância dos fatores vivenciados no ensino superior (e.g., cobranças de desempenho, sobrecarga de tarefas) na determinação dos quadros de estresse e ansiedade, conforme apontado por Bardagi e Hutz (2011).

Na primeira avaliação realizada, dentre os 11 participantes, apenas 1 não teve manifestação de estresse, enquanto que os demais estavam na fase de resistência do estresse, indicando estarem no curso de uma vivência mais prolongada com os estressores (Lipp, 2005). Além disso, houve predominância de sintomas psicológicos do estresse, em detrimento de sintomas físicos, conforme também encontrado nos estudos revisados por Bardagi e Hutz (2011). Já com relação à ansiedade, 3 participantes apresentaram grau mínimo e 4 apresentaram grau leve, indicando menor prevalência desse indicador emocional na primeira avaliação (pré-teste).

Esses resultados elevados nos escores emocionais podem indicar que os participantes apresentavam alguma dificuldade para lidar com os desafios inerentes ao ensino superior (Bardagi, \& Hutz, 2011), o que aponta para a necessidade de intervenções com essa população (Amaral et al., 2012; Ambiel et al., 2016; Garcia et al., 2015). Já que a identificação e satisfação com a carreira tendem a promover bem-estar psicológico (Bardagi et al., 2003; Buscacio, \& Soares, 2017), e como a maior parte dos universitários estava muito satisfeita e encontrava-se identificada com o curso superior, hipotetizase que os elevados níveis de estresse e ansiedade não eram decorrentes da falta de identificação com a carreira escolhida, nem com insatisfações relacionadas ao curso, mas sim dificuldades para lidar com as exigências inerentes ao contexto acadêmico ou a fatores de ordem pessoal, não investigados por esta pesquisa, a exemplo do que apontam outros estudos da literatura (Bonifácio et al., 2011; 
Moreno, \& Soares, 2014; Porto, \& Soares, 2017; Soares et al., 2014).

Em uma análise mais individualizada, observa-se que a participante $\mathrm{P} 4$ foi a que apresentou ansiedade em sua maior gravidade, assim como estresse elevado no pré-teste (Tabela 3). Interessante notar que essa participante, do curso de Nutrição, indicou estar no $12^{\mathrm{o}}$ período (Tabela 1). Porém, salienta-se que esse curso é composto por 8 períodos, sendo, portanto, integralizado em 4 anos, o que indica que essa aluna, provavelmente, estava bastante atrasada no curso, ou seja, alguma dificuldade para concluí-lo, o que pode ter contribuído para ter apresentado os piores indicadores emocionais entre o grupo pesquisado na $1^{\text {a }}$ avaliação, uma vez que, conforme apontado por Pereira et al. (2014), a retenção causa prejuízos pessoais aos estudantes. Assim, é importante a oferta de programas de apoio acadêmico para diminuir a retenção (Amaral et al., 2012), que pode ser fator de risco para desenvolvimento de quadros de estresse e ansiedade. Também chamam a atenção os escores de P7, do curso de Letras, que não apresentou estresse nem ansiedade no pré-teste e se manteve assim após a participação na Oficina (Tabelas 1 e 3).

A análise comparativa destacou a redução dos escores de estresse para apenas 2 participantes do pré para o pós-teste $(8$ participantes permaneceram com o mesmo escore e 1 participante teve os seus escores/níveis agravados), indicando que as oficinas em grupo realizadas podem ter contribuído pouco para a redução desses indicadores emocionais na população avaliada. Já os níveis de ansiedade podem ter sido mais afetados pela proposta de intervenção, haja vista que 6 participantes tiveram redução dos escores pós-teste, enquanto que 2 participantes tiveram seus escores aumentados e 3 mantiveram o mesmo escore no pré e pós-teste (Tabela 3). O suporte social proporcionado por grupos dessa natureza, bem como a possibilidade dos estudantes falarem sobre suas angústias e ansiedades podem ter sido fatores relacionados à diminuição da ansiedade, conforme os achados da literatura sobre o papel de intervenções em grupo nesses aspectos (Chagas et al., 2013; Furlan, 2013; Oliveira et al., 2013). Intervenções dessa natureza podem favorecer a aprendizagem de estratégias de enfrentamento do estresse (coping) frente a problemas comuns no contexto acadêmico: a falta de organização do tempo, a ausência de motivação e de habilidades para o estudo, déficits de habilidades sociais, dentre outros (Basso et al., 2013; Lopes et al., 2017).

No que se refere à avaliação da proposta implementada, os estudantes tiveram uma percepção positiva das Oficinas, de acordo com os escores do ISU, apontando que as Oficinas contribuíram com o aprendizado de estratégias que os deixaram mais confiantes para lidar com o estresse e a ansiedade. As atividades que os participantes avaliaram como sendo mais interessantes, reforçam a importância desse tipo de intervenção para proporcionar autoconhecimento, autocontrole e o suporte social entre os participantes e, consequentemente, diminuir indicadores emocionais de estresse e ansiedade, conforme apontado por outros estudos (Aragão et al., 2009; Borine et al., 2015; Hirsch et al., 2015).

Como a pesquisa foi realizada em um contexto de intervenção, no qual nem sempre é possível realizar um controle rigoroso de variáveis, e sem a existência de um grupo controle, não se pode afirmar com certeza que a Oficina foi (ou não) responsável pela mudança nos escores de estresse e ansiedade na população pesquisada, sendo essa uma das limitações da presente pesquisa. Um fator importante nessa análise refere-se ao período no qual a coleta de dados do pós-teste foi conduzida: coincidiu com a aproximação do final do período, o que pode ter influenciado os resultados do pós-teste. Sugere-se que pesquisas futuras, em contextos de intervenção, adotem, se possível, esse controle das variáveis de interesse.

\section{Considerações finais}


Este trabalho teve como objetivo avaliar indicadores de ansiedade e estresse antes e após a participação de universitários em oficinas de Controle de Ansiedade e Enfrentamento do Estresse, desenvolvidas a partir dos princípios da clínica analíticocomportamental. As análises realizadas indicaram que a população universitária pesquisada apresentou dificuldades de autorregulação das emoções, dado os altos escores de ansiedade e estresse obtidos na avaliação anterior à participação nas oficinas. Houve relevante redução do estresse e diminuição da gravidade da ansiedade à maioria dos universitários, após a participação nas oficinas, que foram positivamente avaliadas por eles.
A necessidade de ajustamento às demandas acadêmicas foi apontada pelos participantes, em suas verbalizações nas oficinas, como fator gerador de estresse e ansiedade. Assim, sugere-se a implementação de programas de apoio psicológico ao estudante como forma de desenvolvimento das habilidades necessárias para o sucesso acadêmico, o que contribuirá com a melhoria de seu bem-estar psicológico. Tais intervenções podem favorecer o desenvolvimento de novos repertórios comportamentais, a exemplo das duas oficinas aqui apresentadas, e facilitar o processo de adaptação e enfrentamento do universitário ao ensino superior, com possíveis reflexos em seu desempenho acadêmico.

\section{Referências}

Alves, J. G. B. (2010). Qualidade de vida em estudantes de Medicina no início e final do curso: Avaliação pelo Whoqol-bref. Revista Brasileira de Educação Médica, 34(1), 9196. doi: 10.1590/S010055022010000100011

Amaral, A. E. V., Silva, M. A., Lopes, F. L., Leite, C. A., Luca, L., \& Rodrigues, T. C. (2012). Programa de acolhimento a universitários: Relato de experiência em clínica-escola. Encontro Revista de Psicologia, 15(23), 27-35. Recuperado de http://www.pgsskroton.com.br/seer/index.p hp/renc/article/view/2465/2362

Ambiel, R. A. M., Santos, A. A. A., \& Dalbosco, S. N. P. (2016). Motivos de evasão, vivências acadêmicas e adaptabilidade de carreira em universitários. Psico (Porto Alegre), 47(4), 288-297. doi: 10.15448/19808623.2016.4.23872

Aragão, E. I. S., Vieira, S. S., Alves, M. G. G., \& Santos, A. F. (2009). Suporte Social e Estresse: Uma revisão da literatura. Psicologia em Foco, 2(1), 79-90. Recuperado de http://linux.alfamaweb.com.br/sgw/downlo ads/161_115245_ARTIGO8-

Suportesocialeestresseumarevisaodaliteratura.pdf
Bardagi, M. P., \& Hutz, C. S. (2005). Evasão universitária e serviços de apoio ao estudante: Uma breve revisão da literatura brasileira. Psicologia Revista, 14(2), 279301. Recuperado de https://revistas.pucsp.br/index.php/psicorev ista/article/view/18107/13463

Bardagi, M. P., \& Hutz, C. S. (2011). Eventos estressores no contexto acadêmico: Uma breve revisão da literatura brasileira. Interação em Psicologia, 15(1), 111-119. doi: 10.5380/psi.v15i1.17085

Bardagi, M. P., Lassance, M. C. P., \& Paradiso, A. C. (2003). Trajetória acadêmica e satisfação com a escolha profissional de universitários em meio de curso. Revista Brasileira de Orientação Profissional, 4(1-2), 153-166. Recuperado de http://pepsic.bvsalud.org/pdf/rbop/v4n12/v4n1-2a13.pdf

Basso, C., Graf, L. P., Lima, F. C., Schmidt, B., \& Bardagi, M. P. (2013). Organização de tempo e métodos de estudos: Oficinas com estudantes universitários. Revista Brasileira de Orientação Profissional, 14(2), 277-288. Recuperado de http://pepsic.bvsalud.org/scielo.php?script= sci_arttext\&pid=S167933902013000200012 
Beutler, L. E. \& Clarkin, J. F. (2014). Systematic Treatment Selection: Toward targeted therapeutic interventions. Abingdon: Routledge.

Bisinoto, C., Marinho, C., \& Almeida, L. (2011). A atuação da Psicologia Escolar na educação superior: Algumas reflexões. Revista Portuguesa de Pedagogia, 45(1), 39-55. Recuperado de https://www.researchgate.net/publication/2 70537975_A_atuacao_da_psicologia_escol ar_na_educacao_superior_algumas_reflexo es

Bolsoni-Silva, A. T, \& Carrara, K. (2010).

Habilidades sociais e análise do comportamento: compatibilidades e dissensões conceitualmetodológicas. Psicologia em Revista, 16(2), 330-350. Recuperado de http://pepsic.bvsalud.org/scielo.php?script= sci_arttext\&pid=S1677-

$11682010000200007 \& \operatorname{lng}=\mathrm{pt} \& \ln \mathrm{g}=\mathrm{pt}$.

Bolsoni-Silva, A. T., Leme, V. B. R., Lima, A. M. A. D., Costa-Júnior, F. M. D., \& Correia, M. R. G. (2009). Avaliação de um treinamento de habilidades sociais (THS) com universitários e recém-formados. Interação em Psicologia, 13(2), 241-251.

Bonifácio, S. P., Silva, R. C. B., Montesano, F. T., \& Padovani, R.

C. (2011). Investigação e manejo de eventos estressores entre estudantes de Psicologia. Revista Brasileira de Terapias Cognitivas, 7(1), 15-20. Recuperado de http://pepsic.bvsalud.org/scielo.php?script= sci_arttext\&pid=S1808-

56872011000100004

Borges, N. B., \& Cassas, F. A. (2012). Clínica analítico-comportamental: aspectos teóricos e práticos. Porto Alegre: Artes Médicas.

Borine, R. C. C., Wanderley, K. S., \& Bassitt, D. P. (2015). Relação entre a qualidade de vida e o estresse em acadêmicos da área da saúde. Estudos Interdisciplinares em Psicologia, 6(1), 100-118. doi: 10.5433/2236-6407.2015v6n1p100

Bravim, A. A., \& Farias, A. K. C. R. (2011). Análise comportamental do Transtorno de Ansiedade Generalizada
(TAG): implicações para avaliação e tratamento. In A. K. C. R. Farias (Org.), Análise Comportamental Clínica: Aspectos Teóricos e Estudos de Caso. Porto Alegre: Artmed.

Buscacio, R. C. Z., \& Soares, A. B. (2017). Expectativas sobre o desenvolvimento da carreira em estudantes universitários. Revista Brasileira de Orientação Profissional, 18(1), 69-79. doi: 10.26707/1984-7270/2017v18n1p69

Casari, L. M., Anglada, J., \& Daher, C. (2014). Estrategias de afrontamiento y ansiedad ante exámenes en estudiantes universitarios. Revista de Psicología, 32(2), 243-269.

Chagas, M. T, Guilherme, G., \& Moriyama, J. S. (2013). Intervenção clínica em grupo baseada na terapia de aceitação e compromisso: Manejo da ansiedade. Acta Comportamentalia, 21(4), 495-508.

Recuperado de http://www.revistas.unam.mx/index.php/ac om/article/view/43612

Corral-Mulato, S., Baldissera, V. D. A., Santos, J. L., Philbert, L. A. S., \& Bueno, S. M. V. (2011). Estresse na vida do acadêmico em Enfermagem:

(Des)conhecimento e prevenção. Investigación y Educación en Enfermería, 29(1), 109-117. Recuperado de http://aprendeenlinea.udea.edu.co/revistas/i ndex.php/iee/article/view/6595/7923

Cruz, C. M. V. M., Pinto, J. R., Almeida, M., \& Aleluia, S. (2010). Ansiedade nos estudantes do ensino superior: Um estudo com estudantes do $4^{\circ}$ ano do curso de licenciatura em Enfermagem da Escola Superior de Saúde de Viseu. Revista Millenium, 15(38), 223-242. Recuperado de http://repositorio.ipv.pt/handle/10400.19/30 5

Cunha, E. R.; \& Morosini, M. C. (2013). Evasão na Educação Superior: Uma temática em discussão. Revista Cocar, 7(14), 82-89. Recuperado de https://paginas.uepa.br/seer/index.php/coca r/article/view/283 
Cunha, J. A. (2001). Manual da versão em português das Escalas Beck. São

Paulo: Casa do Psicólogo.

Del Prette, A. \& Del Prette, Z.A.P. (2003). No contexto da travessia para o ambiente de trabalho: Treinamento de habilidades sociais com universitários. Estudos de Psicologia (Natal), 8(3), 413-420.

Del Prette, A., \& Del Prette, Z. A. P. (2001). Psicologia das relações interpessoais: Vivências para o trabalho em grupo. Petrópolis: Vozes.

Eyberg, S. M. (1993). Consumer satisfaction measures for assessing parent training programs. Innovations in Clinical Practice: A source book, 12(1), 377-382.

Ferreira, C. L., Almondes, K. M., Braga, L. P., Mata, A. N. S., Lemos, C. A., \& Maia, E. M. C. (2009). Universidade, contexto ansiogênico? Avaliação de traço e estado de ansiedade em estudantes do ciclo básico. Ciência e Saúde Coletiva, 14(3), 973-981. Recuperado de http://www.scielo.br/pdf/csc/v14n3/33.pdf

Ferreira, V. S., Oliveira, M. A., \& Vandenberghe, L. (2014). Efeitos a curto e longo prazo de um grupo de desenvolvimento de habilidades sociais para universitários. Psicologia: Teoria e Pesquisa, 30(1), 73-81. Recuperado de http://www.scielo.br/pdf/ptp/v30n1/09.pdf

Furlan, L. A. (2013). Eficacia de la Intervención para Disminuir la Ansiedad frente a los Exámenao en Estudiantes Universitarios. Revista Colombiana de Psicología, 22(1), 75-89. Recuperado de http://www.redalyc.org/articulo.oa?id=804 28081006

Garcia, V. A., Bolsoni-Silva, A. T, \& Nobile, G. F. G. (2015). A Interação Terapêutica em Intervenções com Universitários com Transtorno de Ansiedade Social. Psicologia: Ciência e Profissão, 35(4), 1089-1105. Recuperado de http://www.scielo.br/pdf/pcp/v35n4/19823703-pcp-35-4-1089.pdf

García-Ros, R., Pérez-Gonzaléz, F., PérezBlasco, J., \& Natividad, L. A. (2012). Evaluación del estrés acadéaoco en estudiantes de nueva incorporación a la universidad. Revista Latinoamericana de Psicología, 44(2), 143-154. doi: 10.14349/rlp.v44i2.1038

Gerk, E., \& Cunha, S.M. (2006). As habilidades sociais na adaptação de estudantes ao ensino superior. Em: M. Bandeira, Z. A. P. Del Prette, \& A. Del Prette (Orgs.) Estudos sobre habilidades sociais e relacionamento interpessoal (pp.181-198). São Paulo: Casa do Psicólogo.

Guilhardi, H. J. (2012). AssertividadeInassertividade em um referencial comportamental. Instituto de Terapia por Contingências de Reforçamento. Campinas, SP. Recuperado de http://itcrcampinas.com.br/txt/assertividade .pdf

Hirsch, C. D., Barlem, E. L. D., Almeida, L. K., Tomaschewski-Barlem, J. G., Figueira, A. B., \& Lunardi, V. L. (2015). Estratégias de coping de acadêmicos de enfermagem diante do estresse universitário. Revista Brasileira de Enfermagem, 68(5), 783-790. doi: 10.1590/0034-7167.2015680503i.

Jardim, A. P., \& Ramos, F. P. (2017). Desenvolvimento de Instrumento de Triagem Psicológica, versão 2017. Material não-publicado.

Karino, C. A., \& Laros, J.

A. (2014). Ansiedade em situações de prova: Evidências de validade de duas escalas. Psico-USF, 19(1), 23-36. Doi: 10.1590/S1413-82712014000100004

Lantyer, A. S., Varanda, C. C., Souza, F. G., Padovani, R. C., \& Viana, M. B. (2016). Ansiedade e qualidade de vida entre estudantes universitários ingressantes: Avaliação e intervenção. Revista Brasileira de Terapia Comportamental e Cognitiva, 18(2), 4-19. Doi: 10.31505/rbtcc.v18i2.880

Liébana-Presa, C., Fernández-Martínez, M. E., Gándara, A. R., Muñoz-Villanueva, M. C., Vázquez-Casares, A. M., \& RodríguezBorrego, M. A. (2014). Mal-estar psicológico em estudantes universitários de ciências da saúde e sua relação com o 
Engagement. Revista da Escola de

Enfermagem da USP, 48(4), 715-722. doi: 10.1590/S0080-623420140000400020

Lipp, M. E. N. (2005). Manual do Inventário de Sintomas de Stress para adultos de Lipp. São Paulo: Casa do Psicólogo.

Lopes, D. C., Dascanio, D., Ferreira, B. C., Del Prette, A., \& Del Prette, Z. A. P. (2017). Treinamento de habilidades sociais: Avaliação de um programa de desenvolvimento interpessoal profissional para universitários de ciências exatas. Interação em Psicologia, 21(1), 55-65. Doi: 10.5380/psi.v21i1.36210

Martim, G., \& Silveira, J. (2017). A tarefa de casa na Psicoterapia Analítica

Funcional. Revista Brasileira de Terapia Comportamental e Cognitiva, 19(3), 63-76. Doi: 10.31505/rbtcc.v19i3.1055

Melo, W. V., Peixoto, M., Oliveira, A., \& Bizarro, L. (2012). Avaliação da ansiedade e do processamento da atenção em universitários através da tarefa de Stroop Emocional. Revista Brasileira de Terapia Comportamental e Cognitiva, 14(2), 23-35. Doi: /10.31505/rbtcc.v14i2.505

Morais, L. M., Mascarenhas, S., \& Ribeiro, J. L. P. (2010). Diagnóstico do estresse, ansiedade e depressão em universitários: Desafios para um serviço de orientação e promoção da saúde psicológica na univeridade - Um estudo com estudantes dUFAM - Brasil. Revista AMAzônica, 4(1), 55-76. Recuperado de https://www.researchgate.net/publication/2 59671176

Moreira, S. N. T., Vasconcellos, R. L. S. S., \& Heath, N. (2015). Estresse na Formação médica: Como lidar com essa realidade? Revista Brasileira de Educação Médica, 39(4), 558-564. doi: 10.1590/1981-52712015v39n4e03072014.

Moreno, P. F., \& Soares, A. B. (2014). O que vai acontecer quando eu estiver na universidade? Expectativas de jovens estudantes brasileiros. Aletheia, 45(1), 114127. Recuperado de http://pepsic.bvsalud.org/scielo.php?script= sci_arttext\&pid=S141303942014000200009
Oliveira, C. T., Carlotto, R. C., Teixeira, M. A. P., \& Dias, A. C. G. (2016). Oficinas de gestão de tempo com estudantes universitários. Psicologia: Ciência e Profissão, 36(1), 224-233. doi: 10.1590/1982-3703001482014

Oliveira, C. T., Carlotto, R. C., Vasconcelos, S. J. L., \& Dias, A. C. G.

(2014). Adaptação acadêmica e coping em estudantes universitários brasileiros: Uma revisão de literatura. Revista Brasileira de Orientação Profissional, 15(2), 177-186.

Recuperado de http://pepsic.bvsalud.org/scielo.php?script= sci_arttext\&pid=S167933902014000200008

Oliveira, C. T., Dias, A. C. G., \& Piccoloto, N. M. (2013). Contribuições da terapia cognitivo-comportamental para as dificuldades de adaptação acadêmica. Revista Brasileira de Terapia Cognitiva, 9(1), 10-18. doi: 10.5935/18085687.20130003

Otero, V. R. L. (2004). Ensaio comportamental. Em: C. N. Abreu, \& H. J. Guilhardi. Terapia Comportamental e Cognitivo-comportamental: práticas clínicas (pp. 205-214). São Paulo: Roca.

Padovani, R. C., Neufeld, C. B., Maltoni, J., Barbosa, L. N. F., Souza, W. F., Cavalcanti, H. A. F., \& Lameu, J. N. (2014). Vulnerabilidade e bem-estar psicológico do estudante universitário. Revista Brasileira de Terapias Cognitivas, 10(1), 2-10. doi: 10.5935/1808-5687.20140002

Pereira, A. S., Carneiro, T. C. J., Brasil, G. H., \& Corassa, M. A. C. (2014). Fatores relevantes no processo de permanência prolongada de discentes nos cursos de graduação presencial: Um estudo na Universidade Federal do Espírito Santo. Ensaio Avaliação e Políticas Públicas em Educação, 23 (89), 1015-1039. doi: 10.1590/S0104-40362015000400009

Piemontesi S. E., Heredia, D. E., Furlan, L. A., Sánchez-Rosas, J., \& Martínez, M. (2012). Ansiedad ante los exámenes y estilos de afrontamiento ante el estrés 
acaaomico en estudiantes universitários.

Anales de Psicología, 28(1), 89-96.

Recuperado de

http://www.redalyc.org/articulo.oa?id=167 23161011

Porto, A. M. S., \& Soares, A. B. (2017).

Diferenças entre expectativas e adaptação acadêmica de universitários de diversas áreas do conhecimento. Análise

Psicológica, 1(34), 13-24. doi:

10.14417/ap.1170

Pureza, J. R., Rusch, S. G. S., Wagner, M., \& Oliveira, M. S. (2012). Treinamento de habilidades sociais em universitários: uma proposta de intervenção. Revista Brasileira de Terapias Cognitivas, 8(1), pp. 2-9.

Ramos, F. P., Enumo, S. R. F., \& Paula, K. M. P. (2015). Teoria Motivacional do Coping: Uma proposta desenvolvimentista de análise do enfrentamento do estresse. Estudos de Psicologia, 32(2), 269279. doi: 10.1590/0103166X2015000200011

Rosário, P., Nunes, T., Magalhães, C., Rodrigues, A., Pinto, R., \& Ferreira. (2010). Processos de auto-regulação da aprendizagem em alunos com insucesso no $1^{\circ}$ ano de universidade. Revista Semestral da Associação Brasileira de Psicologia Escolar e Educacional, 14(2), 349-358. doi: 10.1590/S1413-85572010000200017

Santos, A. S., Souto, D. C., Silveira, K. S. S., Perrone, C. M., \& Dias, A. C. G. (2015). Atuação do Psicólogo Escolar e Educacional no ensino superior: Reflexões sobre práticas. Revista Quadrimestral da Associação Brasileira de Psicologia Escolar e Educacional, 19(3), 515-524. doi: 10.1590/2175-3539/2015/0193888

Skinner, E. A., Pitzer, J. R., \& Brule, H. A. (2014). The role of emotion in engagement, coping, and the development of motivational resilience. In: R. Pekrun, \& Linnenbrink-Garcia, L.

(Orgs.), International Handbook of

Emotions and Education (pp. 331-347).

New York: Taylor \& Francis.

Soares, A. B., Francischetto, V., Dutra, B. M., Miranda, J. M., Nogueira, C. C. C., Leme, V. R., Araújo, A. M., \& Almeida, L. S. (2014). O impacto das expectativas na adaptação acadêmica dos estudantes no Ensino Superior. Psico-USF, 19(1), 49-60. Doi: 10.1590/S1413-82712014000100006

Teixeira, M. A. P.; Castro, A. K. S. S., \& Zoltowski, A. P. C. (2012). Integração acadêmica e integração social nas primeiras semanas na universidade: Percepções de estudantes universitários. Gerais: Revista Interinstitucional de Psicologia, 5(1), 6985. Recuperado de http://pepsic.bvsalud.org/scielo.php?script= sci_arttext\&pid=S198382202012000100006

Teixeira, M. O. \& Costa, C. J. (2017). Carreira e bem-estar subjetivo no ensino superior: Determinantes pessoais e situacionais. Revista Brasileira de Orientação Profissional, 18(1), 19-29. doi: 10.26707/1984-7270/2017v18n1p19

Vera, M. N., \& Vila, J. (1996). Técnicas de Relaxamento. In V. E. Caballo. Manual de Técnicas de Terapia e Modificação do Comportamento (pp. 147-166). São Paulo: Santos Editora.

Zeferino, M. T., Hamilton, H., Brands, B., Wright, M. G. M., Cumsille, F., \& Khenti, A. (2015). Consumo de drogas entre estudantes universitários: Família, espiritualidade e entretenimento moderando a influência dos pares. Texto \& Contexto Enfermagem, 24(1), 125-135. doi: 10.1590/0104-07072015001150014. 


\section{Dados sobre os autores:}

- Fabiana Pinheiro Ramos: Possui graduação em Psicologia pela Universidade Federal do Espírito Santo (1999), Mestrado em Psicologia pela Universidade Federal do Espírito Santo (2002) e Doutorado em Psicologia pela Universidade Federal do Espírito Santo (2012). Atualmente, é servidora pública da Universidade Federal do Espírito Santo como professora Adjunta do Departamento de Psicologia. Atualmente desenvolve pesquisas ligadas aos temas: 1) estresse e estratégias de enfrentamento com diferentes populações; 2) avaliação de resultados de intervenções na clínica analítico-comportamental com diversos públicos, especialmente com universitários; 3) violência contra a mulher. Participa do Grupo de Pesquisa em Saúde da Criança e do Adolescente da ANPEPP, e do Grupo de Pesquisa Processos Psicológicos e Saúde do CNPq.

- Nayara Stefenoni Kuster: Possui graduação em Psicologia pela Universidade Federal do Espírito Santo (2017). Realizou estudos sobre as estratégias de enfrentamento do estresse e da ansiedade em jovens universitários. Participou do projeto de extensão: Serviço de Atenção Psicológica ao Graduando da UFES (SAPSIG). Possui o título Jovem Talento para Ciência, (CAPES), 2013. Linhas de pesquisa: psicologia clínica, psicoterapia, enfrentamento do estresse em universitários.

- Juliana Nascimento Lucas Ramalhete: Possui graduação em Psicologia pela Universidade Federal do Espírito Santo (2017). Atualmente é bolsista pesquisadora da FAPES no projeto Ocupação Social. Membro do Grupo de Estudos e Práticas em Avaliação e Mensuração Psicológica (GEPAMP). Desenvolvimento de pesquisa com o tema: Adoecimento Universitário e Intervenção Psicológica pelo Departamento de Psicologia (DPSI) da UFES. Tem experiência nas áreas de Psicologia Social, da Educação, Psicologia Clínica, Avaliação e Mensuração Psicológica, Orientação Profissional e Planejamento de Carreira, Saúde Coletiva e Psicologia Hospitalar.

- Cláudia Porto do Nascimento: Psicóloga (CRP 16/5162), graduada pela Universidade Federal do Espírito Santo (2016). Formação em Terapia Comportamental (2015). Atua como psicóloga clínica realizando atendimentos a crianças, adolescentes e adultos, e como voluntária em um projeto de extensão voltado para a promoção da saúde psicológica de universitários.

\section{Agradecimentos:}

À Pró-reitoria de Pesquisa e Pós-graduação da UFES pela bolsa de Iniciação Científica para a $2^{a}$ autora; à Pró-reitoria de Planejamento e Desenvolvimento Institucional da UFES pela bolsa de Projetos Especiais de Apoio ao Ensino, Pesquisa e Extensão à $3^{\text {a }}$ autora; e aos alunos do Projeto de Extensão "Serviço de Atenção Psicológica ao Graduando da UFES" que viabilizaram a coleta de dados durante a realização das oficinas. 